06.1

\title{
Магнитные характеристики наночастиц магнетита, внедренных из феррожидкости в пористый кремний
}

\author{
() И.В. Плешаков ${ }^{1}$, М.П. Волков ${ }^{1}$, Е.Е. Бибик ${ }^{2}$, Н.В. Глебова ${ }^{1}$, А.А. Нечитайлов ${ }^{1}$, Ю.И. Кузьмин ${ }^{1}$ \\ ${ }^{1}$ Физико-технический институт им. А.Ф. Иоффре РАН, Санкт-Петербург, Россия \\ ${ }^{2}$ Санкт-Петербургский государственный технологический институт (Технический университет), Санкт-Петербург, Россия \\ E-mail: ivanple@yandex.ru
}

Поступило в Редакцию 6 апреля 2021 г.

В окончательной редакции 29 апреля 2021 г.

Принято к публикации 8 мая 2021 г.

\begin{abstract}
Изучены магнитные свойства наноструктуры, полученной внедрением частиц магнетита в каналы пористого кремния из коллоидного раствора $\mathrm{Fe}_{3} \mathrm{O}_{4}$ в керосине. Изучены температурные зависимости параметров этих образцов, установлены их особенности. Сделано предположение, что магнитный материал состоит из двух фракций, одна из которых демонстрирует суперпарамагнитное поведение, а вторая вплоть до комнатной температуры находится в заблокированном состоянии.
\end{abstract}

Ключевые слова: магнитная наноструктура, нанокомпозит, пористый кремний, феррожидкость.

DOI: 10.21883/PJTF.2021.16.51321.18809

Интерес к магнитоупорядоченным наноструктурам определяется тем, что по свойствам они заметно отличаются от объемных образцов и, следовательно, можно ожидать, что путем варьирования размеров наночастиц, методов синтеза магнитного вещества и т. п. на их основе будут созданы материалы с особыми характеристиками. Среди подобных систем большое внимание привлекают разного рода композиты, полученные внедрением магнетика в пористую среду, причем в качестве последней часто рассматривают пористый кремний (por-Si), представляющий собой структуру с развитой внутренней поверхностью [1]. Его каналы могут быть заполнены магнитоупорядоченными веществами. Так, например, в [2] был исследован композит с восстановленным внутри пор металлическим кобальтом. Важной разновидностью применяемых для подобной цели магнетиков являются оксиды, в частности магнетит $\left(\mathrm{Fe}_{3} \mathrm{O}_{4}\right) . \mathrm{Fe}_{3} \mathrm{O}_{4}$, различным образом введенный в матрицу por- $\mathrm{Si}$, подробно изучался с разных точек зрения [3-5]. В некоторых случаях для заполнения пор применялось осаждение наночастиц магнетита из специально подобранного коллоида [6]. Целью настоящей работы является исследование особенностей магнитного поведения образцов, изготовленных с использованием стандартной феррожидкости многофазной среды в виде растворителя и содержащихся в нем магнитоупорядоченных наночастиц [7].

Матрица por-Si была получена методом, описанным в [8]. Процесс представлял собой анодное фотоэлектрохимическое травление ориентированной в плоскости (100) пластины монокристаллического кремния в водноэтанольном растворе плавиковой кислоты. Толщина пластины составляла около $400 \mu \mathrm{m}$. На пластине предварительно создавался рисунок затравочных ямок с периодом $8 \mu \mathrm{m}$. Образовавшиеся в результате травления поры проникали в кремний на глубину $\sim 200 \mu \mathrm{m}$. Их диаметр, приблизительно одинаковый на всем протяжении канала, составлял около $2 \mu \mathrm{m}$. Такая же структура использовалась в [2] для создания композита, содержащего кобальт.

Магнитоупорядоченное вещество вводилось в матрицу посредством пропитывания ее феррожидкостью на основе керосина, содержащей наночастицы $\mathrm{Fe}_{3} \mathrm{O}_{4}$. Она была изготовлена по технологии, включающей синтез $\mathrm{Fe}_{3} \mathrm{O}_{4}$ в водном растворе солей $\mathrm{FeCl}_{3}$ и $\mathrm{FeSO}_{4}$, коллоидизацию за счет добавления аммиака и последующую экстракцию магнетита из реакционной смеси керосиновым раствором олеиновой кислоты. Последняя являлась поверхностно-активным веществом и образовывала на частицах слой, препятствующий их агломерации. Сходные феррожидкости применялись ранее для различных целей, например для внедрения в поры микроструктурированных оптических волокон [9]. Отметим также, что в последние годы они использовались как модельный объект в ряде фундаментальных физических работ [10-12]. Согласно [13], в синтезированных таким способом материалах диаметр наночастиц магнетита распределен по логнормальному закону с медианным значением $8.2 \mathrm{~nm}$ и параметром скейлинга 0.17 (это означает, что практически все частицы имеют размер менее $15 \mathrm{~nm}$ ).

В нашем случае концентрация твердой фазы в жидкости составляла около 2 vol.\%. Жидкость в незначительном количестве наносилась на пластины пористого кремния, после чего проникала в каналы матрицы. Остатки ее осторожно удалялись с поверхности пластин, и далее пластины в течение длительного времени высушивались. В итоге на внутренней поверхности пор сформировалась структура из ферримагнитных частиц. По оценкам, учитывающим указанные выше параметры, вес оксидного материала составляет несколько десятков микрограмм, что согласуется с приводимыми далее 


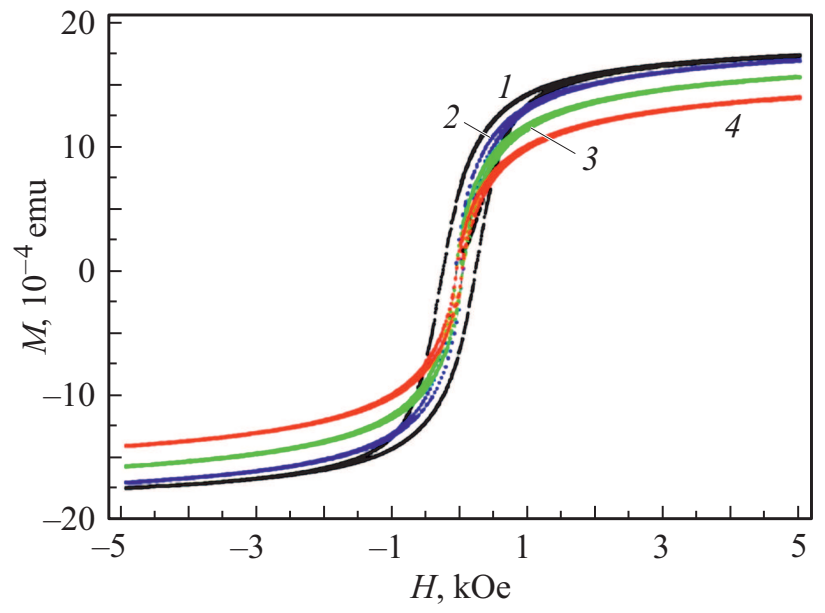

Рис. 1. Кривые намагничивания исследованных образцов при различных температурах. $T$, K: $1-5,2-100,3-200$, $4-300$.

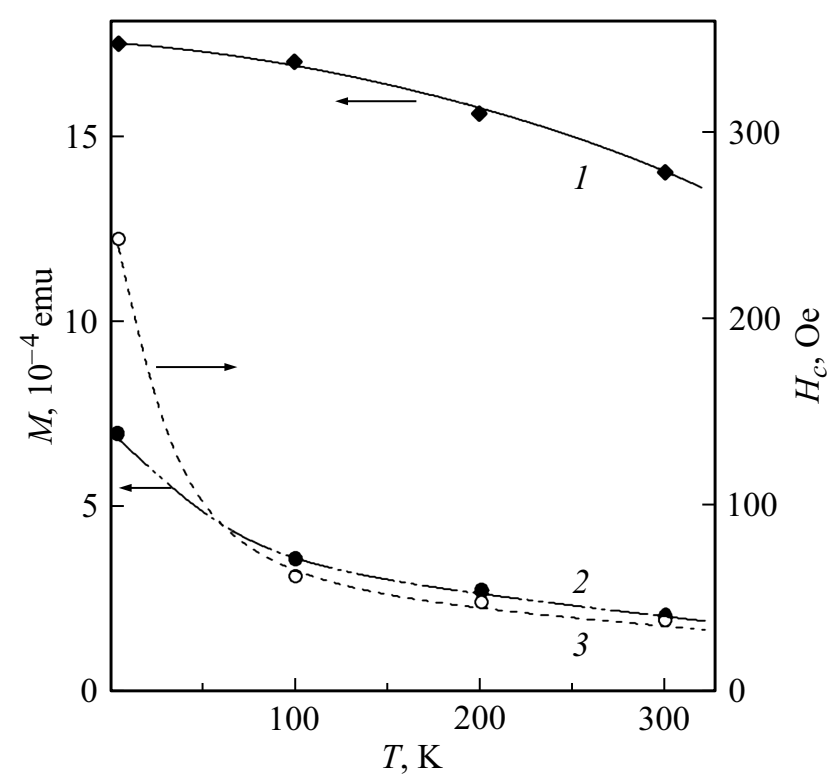

Рис. 2. Температурное поведение параметров петли намагничивания. 1 - магнитный момент насыщения $\left(M_{s a t}\right), 2-$ остаточный магнитный момент $\left(M_{r}\right), 3-$ коэрцитивная сила $\left(H_{c}\right)$.

магнитными характеристиками (и формально соответствует распределению этого вещества по внутренней поверхности пор слоем с толщиной, примерно равной диаметру частицы).

На изготовленных таким способом образцах были выполнены магнитные измерения, которые проводились с помощью вибрационного магнитометра PPMS Quantum Design при ориентации внешнего магнитного поля вдоль пластины. Кривые намагничивания и температурное поведение магнитного момента $M$ образцов были получены в интервале температур от 5 до $300 \mathrm{~K}$.

Зависимости $M$ от магнитного поля $H$ показаны на рис. 1. При всех температурах $T$ наблюдался гистерезис, величина $M$, достигнутая при $H=5 \mathrm{kOe}$ (и принятая нами за магнитный момент насыщения $\left.M_{\text {sat }}\right)$, незначительно увеличивалась при охлаждении. Характер петель несколько различался для разных $T$ : кривые $M(H)$, полученные при $T>5 \mathrm{~K}$, сохраняли приблизительное подобие (совпадение при нормировке на $M_{\text {sat }}$ ), в то время как при $T=5 \mathrm{~K}$ регистрировалось существенное расширение петли. Это иллюстрирует рис. 2, на котором приведены определенные по $M(H)$ температурные зависимости $M_{s a t}$, остаточного магнитного момента $M_{r}$ и коэрцитивной силы $H_{c}$. Видно, что в области низких температур происходят более значительные изменения $M_{r}$ и $H_{c}$, чем при $T>100 \mathrm{~K}$.

Результаты экспериментов по охлаждению образцов в магнитном поле (FC) и без него (ZFC) показаны рис. 3. Кривые $M(T)$, соответствующие охлаждению и нагреву образца в поле $H=1000 \mathrm{Oe}(\mathrm{FC})$, практически сливаются. Приложение такого же поля к образцу, предварительно охлажденному в нулевом поле до $5 \mathrm{~K}$ (ZFC), вызывало быстрый подъем намагниченности до значения, мало (менее чем на 4\%) отличающегося от полученного при FC-измерении. При увеличении температуры ZFC-зависимость проходила через слабо выраженный максимум, сходясь с FC-кривой при $T \approx 150 \mathrm{~K}$ (в увеличенном масштабе это изображено на вставке к рис. 3).

Наличие надежно регистрируемого гистерезиса кривой намагничивания вплоть до комнатной температуры свидетельствует о том, что значительная часть магнитного вещества находится в заблокированном состоянии. Механизм блокировки не совсем ясен, поскольку наночастицы достаточно малы и при этом должны быть изолированы друг от друга оболочками поверхностноактивного вещества (слоем, толщина которого по оценке составляет около $2 \mathrm{~nm}$ ), а также немагнитным слоем

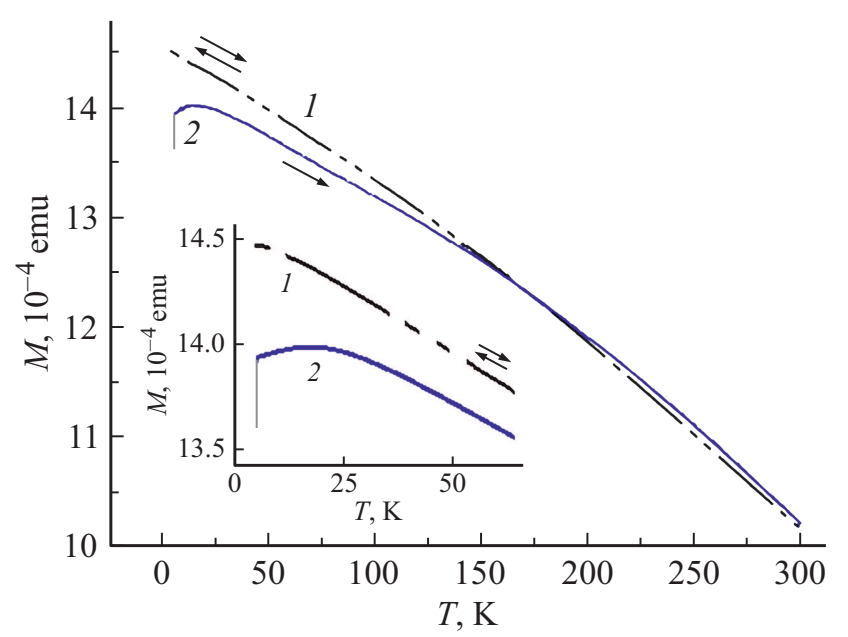

Рис. 3. Результаты FC/ZFC-экспериментов (зависимость магнитного момента $M$ от температуры $T$ ). 1 - охлаждение и нагрев образца в поле $H=1000 \mathrm{Oe}, 2$ - нагрев образца, охлажденного в нулевом поле, в поле $H=1000$ Ое. На вставке увеличенная область низких температур. 
на поверхности магнетита. Это исключает обменное взаимодействие, однако возможно, что определенную роль здесь играют дипольные эффекты [1]. Отметим, что при $T=5 \mathrm{~K}$ остаточная намагниченность равна примерно $40 \%$ от намагниченности насыщения, что очень близко к выполняющемуся в идеальной наноструктуpe при $T=0 \mathrm{~K}$ соотношению $M_{r}=0.5 M_{\text {sat }}$ [14]. Это подтверждает нанодисперсную природу находящегося в порах вещества.

Типичное для суперпарамагнетика поведение, наблюдаемое в FC/ZFC-экспериментах, выражено очень слабо, однако судя по данным, показанным на рис. 3, определенная доля суперпарамагнетика в исследованном материале все же есть. Температура блокировки $T_{B} \approx 17 \mathrm{~K}$, определенная по максимуму ZFC-кривой (рис. 3), лежит достаточно низко, причем следует иметь в виду, что при переходе от $H=1000$ Ое к меньшим полям этот параметр должен дополнительно уменьшиться [1].

Таким образом, экспериментальные результаты, полученные в работе, позволяют сделать предположение о присутствии в исследованном материале двух фракций наноструктурного магнетита: фракции, которая даже при высоких температурах остается заблокированной, и незначительного количества суперпарамагнитной фракции, сохраняющей данное состояние до низких температур. У этого вещества было также отмечено резкое изменение параметров петли намагничивания при температурах ниже $100 \mathrm{~K}$.

\section{Конфликт интересов}

Авторы заявляют, что у них нет конфликта интересов.

\section{Список литературы}

[1] P. Granitzer, K. Rumpf, Materials, 4 (5), 908 (2011). DOI: $10.3390 / \mathrm{ma} 4050908$

[2] А. Lashkul, И.В. Плешаков, Н.В. Глебова, А.А. Нечитайлов, Ю.И. Кузьмин, В.В. Матвеев, Е.Н. Пятышев, А.Н. Казакин, А.В. Глуховской, Письма в ЖТФ, 37 (14), 40 (2011). [Пер. версия: 10.1134/S106378501107025X].

[3] P. Granitzer, K. Rumpf, M. Venkatesan, L. Cabrera, A.G. Roca, M.P. Morales, P. Poelt, M. Albu, K. Ali, M. Reissner, J. Nanopart. Res., 13 (11) 5685 (2011). DOI: $10.1007 / \mathrm{s} 11051-011-0441-9$

[4] T. Uusimäki, G. Margaris, K. Trohidou, P. Granitzer, K. Rumpf, M. Sezen, G. Kothleitner, Nanoscale, 5 (23), 11944 (2013). DOI: 10.1039/c3nr02922k

[5] F.A. Harraza, Appl. Surf. Sci., 287, 203 (2013). DOI: https://doi.org/10.1016/j.apsusc.2013.09.123

[6] P. Granitzer, K. Rumpf, Y. Tian, G. Akkaraju, J. Coffer, P. Poelt, M. Reissner, Appl. Phys. Lett., 102 (19), 193110 (2013). DOI: $10.1063 / 1.4807421$

[7] C. Schere, A.M. Figueiredo Neto, Braz. J. Phys., 35 (3A), 718 (2005). DOI: http://dx.doi.org/10.1590/S0103-97332005000400018

[8] Н.В. Глебова, А.А. Нечитайлов, Письма в ЖТФ, 36 (19), 8 (2010). [Пер. версия: 10.1134/S1063785010100020].
[9] P.M. Agruzov, I.V. Pleshakov, E.E. Bibik, A.V. Shamray, Appl. Phys. Lett., 104 (7), 071108 (2014). DOI: http://doi.org/10.1063/1.4866165

[10] G.L. Klimchitskaya, V.M. Mostepanenko, E.N. Velichko, Phys. Rev. B, 100 (3), 035422 (2019). DOI: https://doi.org/10.1103/PhysRevB.100.035422

[11] E.N. Velichko, G.L. Klimchitskaya, E.K. Nepomnyashchaya, Mod. Phys. Lett. A, 35 (3), 2040016 (2020). DOI: http://dx.doi.org/10.1142/S0217732320400167

[12] E.N. Velichko, G.L. Klimchitskaya, E.N. Nepomnyashchaya, J. Electron. Sci. Technol., 18 (1), 100024 (2020). DOI: $10.1016 /$ j.jnlest.2020.100024

[13] E.E. Bibik, B.Ya. Matygullin, Yu.L. Raikher, M.I. Shliomis, Magnetohydrodynamics, 9 (1), 61 (1973). http://www.mhd.sal.lv/contents/1973/1/MG.9.1.11.R.html

[14] G. Xiao, S.H. Liou, A. Levy, J.N. Taylor, C.L. Chien, Phys. Rev. B, 34 (11), 7573 (1986). DOI: https://doi.org/10.1103/PhysRevB.34.7573 